\title{
Acoustic Surveys of a Scaled-Model CESTOL Transport Aircraft in Static and Forward Speed Conditions
}

\author{
Nathan J. Burnside ${ }^{*}$ and William C. Horne ${ }^{\dagger}$ \\ NASA Ames Research Center, Moffett Field, CA 94035
}

\begin{abstract}
An 11\% scale-model of a Cruise-Efficient Short Take-off and Landing (CESTOL) scalemodel test was recently completed. The test was conducted in the AEDC National Full-Scale Aerodynamic Complex (NFAC) 40- by 80-Foot Wind Tunnel at NASA Ames Research Center. The model included two over-wing pod-mounted turbine propulsion simulators (TPS). The hybrid blended wing-body used a circulation control wing (CCW) with leadingand trailing-edge blowing. The bulk of the test matrix included three forward velocities (40 kts, $60 \mathrm{kts}$, and $100 \mathrm{kts}$ ), angle-of-attack variation between $-5^{\circ}$ and $25^{\circ}$, and $\mathrm{CCW}$ mass flow variation. Seven strut-mounted microphones outboard of the left wing provided source directivity. A phased microphone array was mounted outboard of the right wing for source location. The goal of this paper is to provide a preliminary look at the acoustic data acquired during the Advanced Model for Extreme Lift and Improved Aeroacoustics (AMELIA) test for $0^{\circ}$ angle-of-attack and $0^{\circ}$ sideslip conditions. Data presented provides a good overview of the test conditions and the signal-to-noise quality of the data. TPS height variation showed a difference of $2 \mathrm{~dB}$ to $3 \mathrm{~dB}$ due to wing shielding. Variation of slot mass flow showed increases of $12 \mathrm{~dB}$ to $26 \mathrm{~dB}$ above the airframe noise and the TPS increased the overall levels an additional $5 \mathrm{~dB}$ to $10 \mathrm{~dB}$.
\end{abstract}

\section{Nomenclature}

$\mathrm{C}_{\mathrm{L}} \quad=$ Lift coefficient, $\mathrm{L} /(\mathrm{q} * \mathrm{~S})$

$\mathrm{C} \mu \quad=$ Slot momentum coefficient, $\mathrm{m}^{*} \mathrm{~V}_{\mathrm{j}} /(\mathrm{q} * \mathrm{~S})$

$\mathrm{L} \quad=$ Lift, $\mathrm{lb}_{\mathrm{m}}$

$\mathrm{m}=$ Slot mass flow, $\mathrm{lb}_{\mathrm{m}} / \mathrm{s}$

$\mathrm{M} \quad=$ Mach number

OASPL $=$ Overall sound pressure level, $\mathrm{dB}$ re $20^{-6} \mathrm{~Pa}$

$\mathrm{q}=$ Freestream dynamic pressure, $\mathrm{psf}$

$\mathrm{R}=$ Radial distance from model acoustic center to microphone, inches

$\mathrm{S}=$ Wing planform reference area, $\mathrm{ft}^{2}$

$\mathrm{V}_{\mathrm{j}} \quad=$ Slot jet velocity, $\mathrm{ft} / \mathrm{s}$

$\mathrm{Xw}=$ Wind tunnel coordinate relative to turntable center, positive downstream, inches

$\mathrm{Yw}=$ Wind tunnel coordinate relative to turntable center, positive toward right wall, inches

$\mathrm{Zw}=$ Wind tunnel coordinate relative to turntable, positive up, inches

$\mathrm{Z} / \mathrm{D}=$ Ratio of TPS height to TPS engine inlet diameter

$\Theta=$ Emission angle relative to model acoustic center, $0^{\circ}$ upstream, degrees

\footnotetext{
* Aerospace Engineer, Experimental Aero-Physics Branch, AIAA Senior Member

${ }^{\dagger}$ Aerospace Engineer, Experimental Aero-Physics Branch, AIAA Associate Fellow
} 


\section{Introduction}

$\mathrm{T}$ HE Cruise-Efficient Short Take-off and Landing (CESTOL) configuration concept was developed to meet future requirements of reduced field length, noise, and fuel burn by researchers at $\mathrm{Cal}$ Poly, San Luis Obispo ${ }^{1,2}$ and Georgia Tech Research Institute ${ }^{3,4}$. The novel configuration includes a leading- and trailing-edge circulation control wing $(\mathrm{CCW})$ with over-wing podded turbine propulsion simulation (TPS). The Advanced Model for Extreme Lift and Improved Aeroacoustics (AMELIA) is shown in Fig. 1. Although the primary goal of the AMELIA test was to validate computational fluid dynamics (CFD) using static pressures and balance measurements, it provided an excellent opportunity to make acoustic measurements.

Active lift configurations attempt to maintain attached flow at lower speeds than conventional high-lift systems with flaps and slats. Increased lift coefficients reduce takeoff and landing speeds and distances, or reduce control surface area. Previous active lift studies ${ }^{5,6,7}$ have considered unswept, constant chord configurations with trailing-edge blowing. The present investigation was undertaken to characterize the aerodynamic and aeroacoustic performance of a full-span flight configuration with integrated trailing- and leadingedge slot blowing and over-the-wing turbine propulsion simulators. Several operational parameters were varied: model attitude, thrust level, TPS vertical placement, flap deflection, and slot blowing rate.

\section{Test Facility}

The NFAC facility at NASA Ames Research Center is currently leased and operated by Arnold Engineering Development Center (AEDC) as shown in Fig. 2a. The 40- by 80-Foot Wind Tunnel (40x80) is a closed-circuit wind tunnel, driven by six 40-ft-diameter, 22,550-hp fans. The test section walls are semi-circular with a flat floor and ceiling. The test section is nominally $40 \mathrm{ft}$ high, $80 \mathrm{ft}$ wide, and $80 \mathrm{ft}$ long. An 8:1 contraction accelerates flow and helps to reduce nonuniformity and turbulence $\left(0.5 \%\right.$ stream-wise, $0.7 \%$ cross-stream $\left.{ }^{8}\right)$. The atmospheric wind tunnel has a maximum test-section velocity of 300 knots $(\mathrm{M}=0.45)$.

The test section of the $40 \times 80$ is acoustically treated to minimize reverberation. A porous liner and perforated metal sheet form an aerodynamic surface that covers 42 -inch-deep sound absorbing fiberglass wedges. Figure $2 \mathrm{~b}$ shows the details of the acoustic lining ${ }^{9}$. The acoustic lining absorbs $94 \%$ to $97 \%$ of the acoustic energy between $100 \mathrm{~Hz}$ to $2,500 \mathrm{~Hz}$ and $78 \%$ to $97 \%$ between $4 \mathrm{kHz}$ to $20 \mathrm{kHz}^{10}$. Allen, Jaeger, and Soderman reported measurements of the test section background noise in 2000 using in-flow sensors ${ }^{11}$.
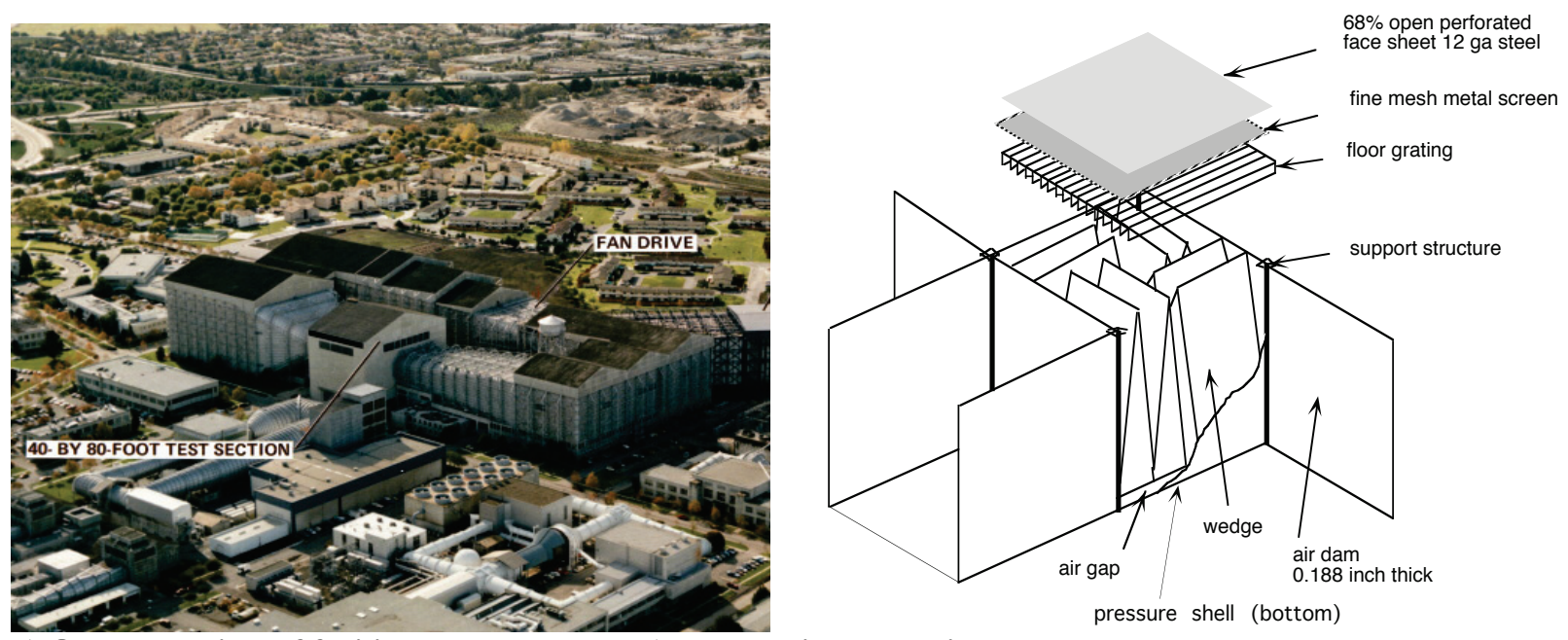

a) Overhead view of facility

b) Test section acoustic treatment

Figure 2. NFAC 40- by 80-Foot Wind Tunnel at NASA Ames. 


\section{Model}

The AMELIA model was designed to validate predictive codes developed for powered-lift. It is an $11 \%$ scalemodel of a 100 passenger, regional, cruise-efficient short take-off and landing airliner with a hybrid blended wingbody with circulation control ${ }^{2}$. The model was sting mounted and included two independent high-pressure air flow paths for the CCW and TPS units. The TPS flow path was routed through a 6-component flow-through balance and the $\mathrm{CCW}$ air was routed through a bellows configuration.

Circulation control consisted of wing leading- and trailing-edge blowing over $95 \%$ of the wing span. Prior to installation, a detailed calibration of the slot was performed by Cal Poly researchers to balance the four CCW plenums, ensuring uniform slot flow at a maximum flow rate of $1.4 \mathrm{lb} / \mathrm{m}$ from each wing. Slot height increased from wing root to tip, however an average slot height of approximately $0.025 \mathrm{in}$. was used for the leading-edge inboard and outboard wing sections. Average heights of 0.025 in. and 0.047 in. were used for trailing-edge outboard and inboard sections, respectively. Table 1 in the Appendix lists the minimum, maximum, an average slot heights for all 8 wing sections. The majority of test was conducted with CCW active on both leading and trailing edges of the wing, however a subset of data was collected with trailing edge only CCW.

Two TPS units built by Tech Development Inc. (TDI) were mounted in engine nacelle pods above the fuselage. The 2-stage TDI 441 TPS units were borrowed from NASA Langley and refurbished by TDI for this test. They were run at a nominal speed of 33,400 RPM, about $77 \%$ of their designed maximum. The TPS units had a fan diameter of 5 inches $(12.7 \mathrm{~cm})$, with 2 stages, and a 3 -stage air motor drive. TPS elevation above the wing surface was varied

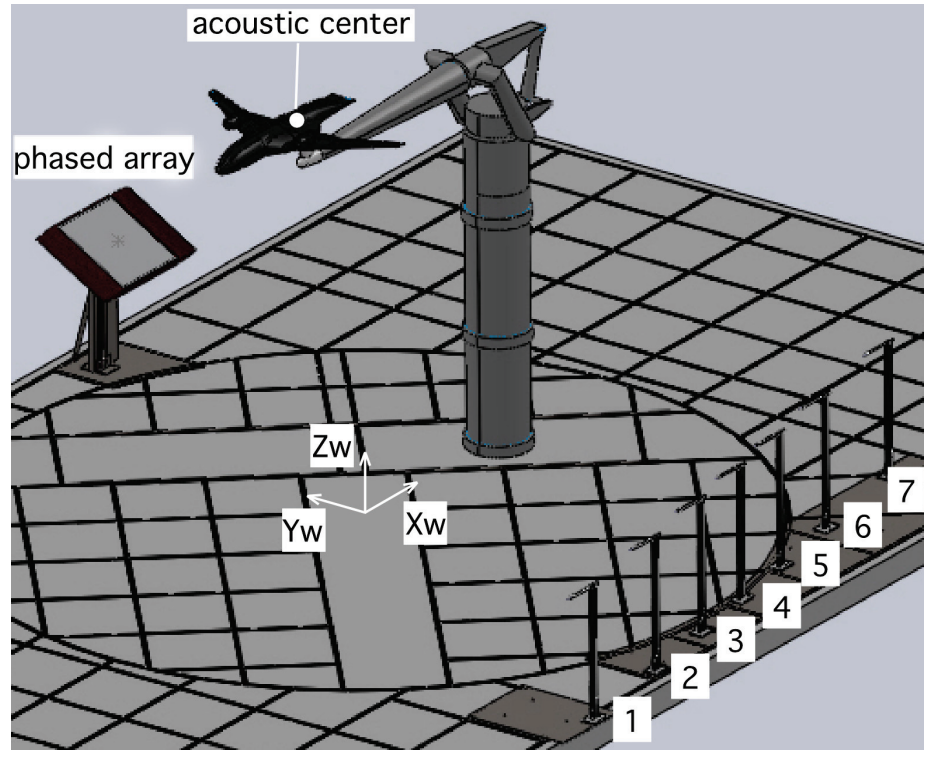

Figure 3. Test section layout used for AMELIA test in the 40x 80-Ft Wind Tunnel. during the test; elevations of 0.84 and 1.25 fan diameters above the model center, referred to as low- and high-pylon elevations respectively.

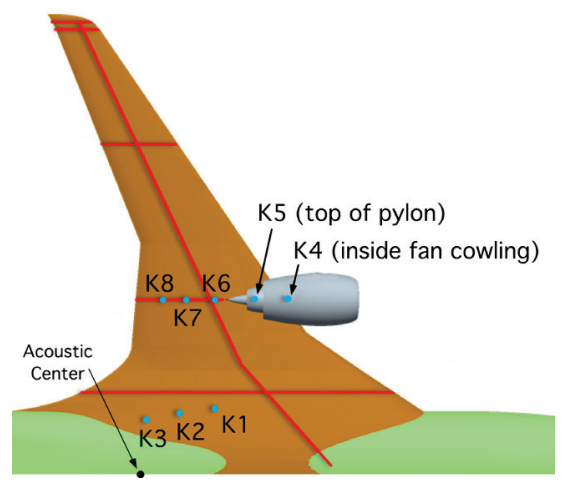

Figure 4. Unsteady surface pressure sensor locations, top view.

\section{Acoustic Instrumentation}

Acoustic instrumentation included fixed microphones, a phased microphone-array, and surface-mounted unsteady pressure sensors. All microphones were G.R.A.S 1/4" free-field condenser type. The unsteady pressure measurements were made using a mix of 5 psi and 15 psi Kulite transducers type XCS-062. All acoustic signals were acquired simultaneously using a National Instruments 24-bit PXI data system. Data were sampled at $102.4 \mathrm{kHz}$ yielding a $40 \mathrm{kHz}$ bandwidth.

Eight unsteady surface pressure transducers were mounted on the model at locations near the TPS nacelle and along the mid-fuselage as shown in Fig. 4. Seven fixed microphones were installed outboard of the left wing and a phased microphone array was outboard of the right wing as shown in Fig. 3. The microphones were staggered so that their turbulence would not impinge on downstream microphones. Emission angles to each microphone are relative to the acoustic center of the model, defined as the point on the stream-wise centerline of the model on a line between the points of sweep change in the wing trailing edges. Figure 3 and 4 show the location of the acoustic 
center. Table 2 located in the Appendix lists the coordinates relative to the wind tunnel coordinate system shown in Fig. 3 and emission angles relative to the acoustic center.

The 48-channel, 40-inch diameter array was mounted in an aerodynamic fairing and recessed behind a porous Kevlar screen ${ }^{12}$. The array pattern and processing software were purchased from Optinav, Inc. In addition to conventional beamforming, the software provides deconvolutional post-processing with CLEAN-SC, DAMAS2, TIDY, and other algorithms, however conventional and TIDY processing were used exclusively for this test.

\section{Experimental Results}

Selected results from the measurements are presented in the following sections to convey a sense of the scope of test conditions, and quality of data with regard to signal-to-noise levels. The data are presented at model scale and physical measurement distances in the wind tunnel. The microphone and array data have not been corrected for directional nosecone or array fairing treatment effects, which can vary from 0 to $10 \mathrm{~dB}$, but more typically around 2 $\mathrm{dB}$. Appropriate scaling and corrections will be accomplished and verified for future reports.

\section{A. Turbo Fan Propulsion Simulator (TPS) Measurements}

The TPS units were not acoustically representative of any full-scale turbo propulsion system, but provided the desired aerodynamic effect on the wing flow. They did provide an intense wide-band acoustic source above the wing for comparative measurements of wing shielding effects, as discussed below. Referring to the overhead view of the wing and TPS in Fig. 4, it can be seen that forward TPS radiation should experience little shielding in the forward arc, but the wing should significantly shield aft TPS radiation. Local pressure sensors K4, K5, and K6 were placed on along the axis TPS to help distinguish forward- from aft-radiated noise, however several of the Kulites failed at the start of the test $(\mathrm{K} 2, \mathrm{~K} 4, \mathrm{~K} 6)$.

Prior to the wind tunnel experiment, the TPS units were tested at Georgia Tech Research Institute (GTRI) in the plume of a free jet to simulate forward speed. The primary objective of this task was to calibrate TPS thrust and mass flow for simulated wind tunnel conditions. Acoustic levels were also acquired in the aft quadrant at radii of 20 $\mathrm{ft}$ and $30 \mathrm{ft}$ and at angles of $110^{\circ}$ to $150^{\circ}$ relative to the forward direction. A typical narrowband spectrum at $120^{\circ}$, 33,400 RPM, and no forward velocity (static) is shown in Fig. 5.

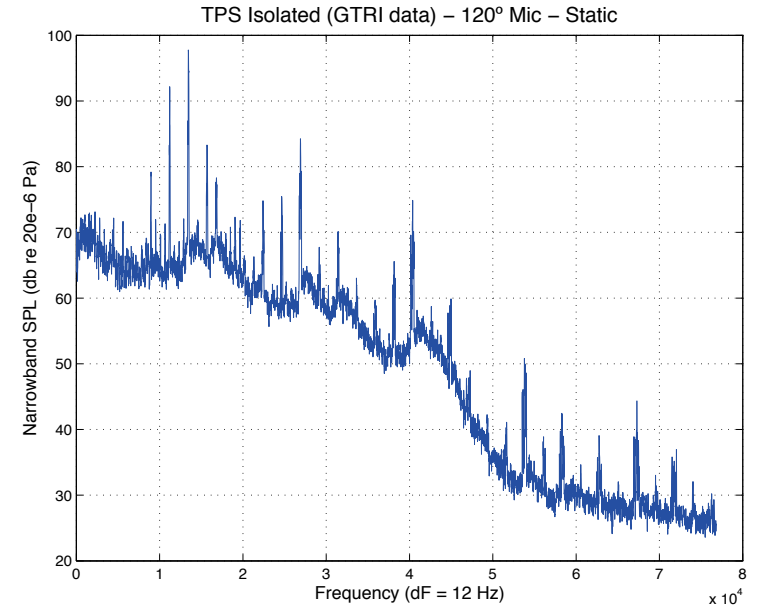

Figure 5. Narrowband spectra of isolated TPS (GTRI) at 33,400 RPM, static, $120^{\circ}, 30 \mathrm{ft}, \Delta \mathrm{f}=12$ Hz.



Figure 6. 1/3-Octave spectra of installed vs isolated TPS, 33,400 RPM, static $140^{\circ}$, data scaled to wind tunnel distance.

A 1/3-octave band comparison of isolated (GTRI) vs installed (low-pylon) is shown in Fig. 6 for the max TPS test condition of 33,400 RPM, with the GTRI data scaled to the wind tunnel measurement distance. A strong fundamental of $98 \mathrm{~dB}$ is seen at $13 \mathrm{kHz}$, followed by a harmonic level of $88 \mathrm{~dB}$ at $26 \mathrm{kHz}$. Differences between the installed and isolated levels are on the order of 2-5 dB.

The placement of the propulsion unit above the wing was chosen to allow the wing to obstruct some of noise propagating towards the ground, and to determine the aerodynamic effects of this configuration. During the test, the TPS height above the wing was varied with pylons of two different heights $(\mathrm{Z} / \mathrm{D}=0.84$ and 1.25$)$, but the span- and 


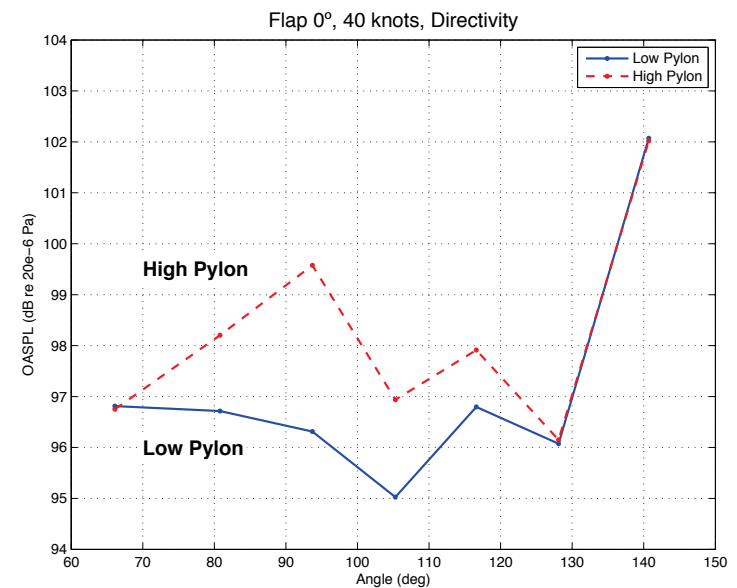

Figure 7. OASPL comparison of low- vs highpylon directivity at $40 \mathrm{kts}$, flap $0^{\circ}$.

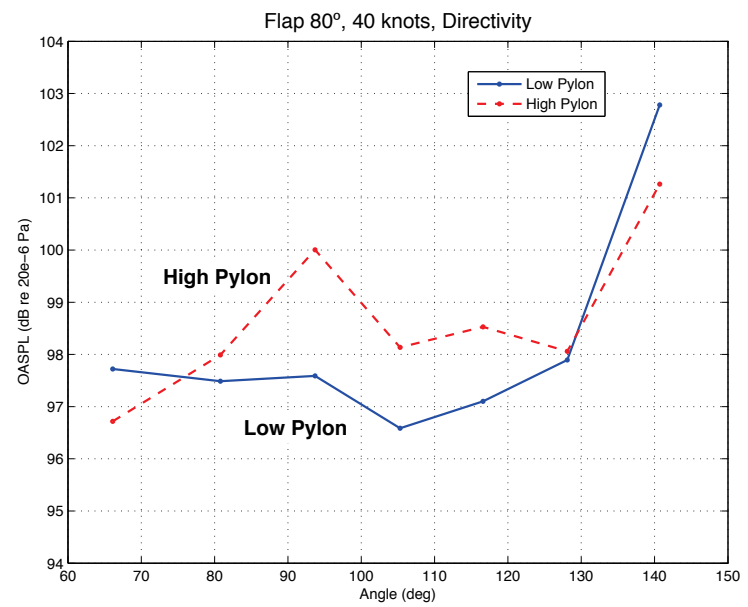

Figure 9. OASPL spectra comparison of low- vs high-pylon directivity at $40 \mathrm{kts}$, flap $80^{\circ}$.



Figure 8. OASPL comparison of low- vs highpylon directivity at $40 \mathrm{kts}$, flap $60^{\circ}$.

chord-wise placements were not varied. Comparisons of the high- and low-pylon directivities of OASPL at 40 kts for flap angles of $0^{\circ}, 60^{\circ}$, and $80^{\circ}$ are shown in Figs. 7,8 , and 9 , respectively. The low pylon configuration was expected to provide greater wing shielding, and this trend is observed in the range of $70^{\circ}$ to $130^{\circ}$ for the three flap angles, with a $2 \mathrm{~dB}$ to $3 \mathrm{~dB}$ difference in shielding effect for the two pylon heights.

The TPS units are expected to generate a complex source distribution, with forward- and aft-radiated fan/turbine and jet noise. Further analysis of the data, including signals from the unsteady pressure data is planned to provide a better understanding of the source, however the primary benefit of the TPS operation is a realistic simulation of the aerodynamic propulsion installation effects. Useful acoustic models of this configuration will more likely be based on propulsion systems more representative of flight systems.

\section{B. Slot-Blowing Active Lift Noise}

The AMELIA test provided an excellent opportunity to document the noise associated with blown trailing- and leading-edge (TE and LE) slots. A cross-section of the wing at $80^{\circ}$ flap is shown in Fig. 10, which depicts the separate TE and LE plenums as well as the slot nozzle exits. Measurements were acquired with both TE and LE slots active, as well as with TE only active. While this concept has been analyzed and tested in numerous variations over the years, the AMELIA test provided a new and unique set of aerodynamic and acoustic measurements to help improve the understanding of active lift on a realistic flight configuration.

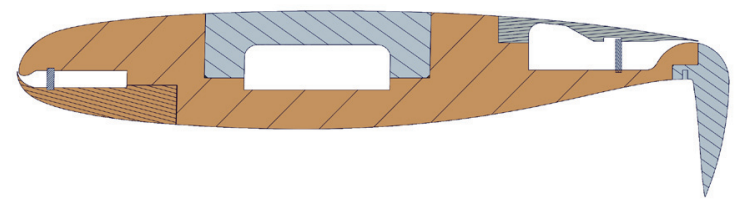

a)



b)

Figure 10. Wing cross section of slot plenums and exits, flap $80^{\circ}$, a) inboard cut 26 in. from model center, b) outboard cut 50 in. from model center. 

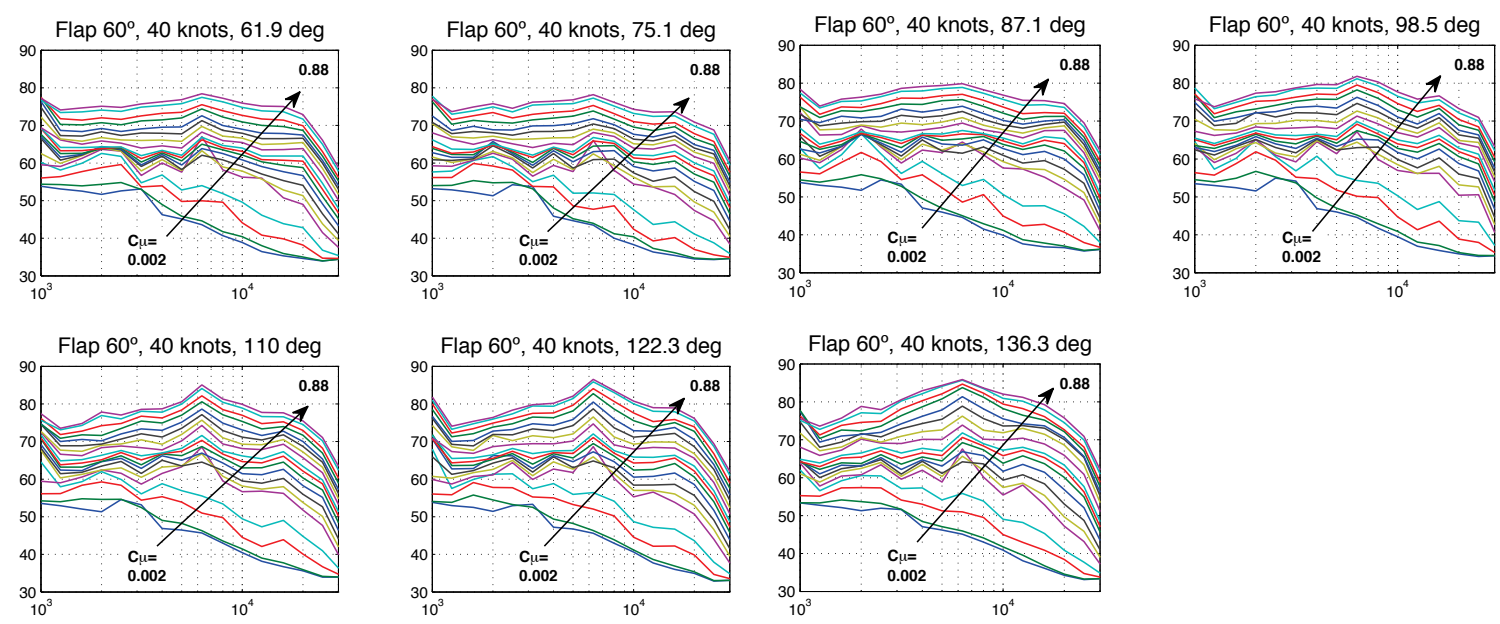

Figure 11. Effect of slot mass flow rate on 1/3-octave spectra for 7 microphones, $40 \mathrm{kts}$, flap $60^{\circ}, 0.002$ $\leq \mathrm{C} \mu \leq \mathbf{0 . 8 8}$.

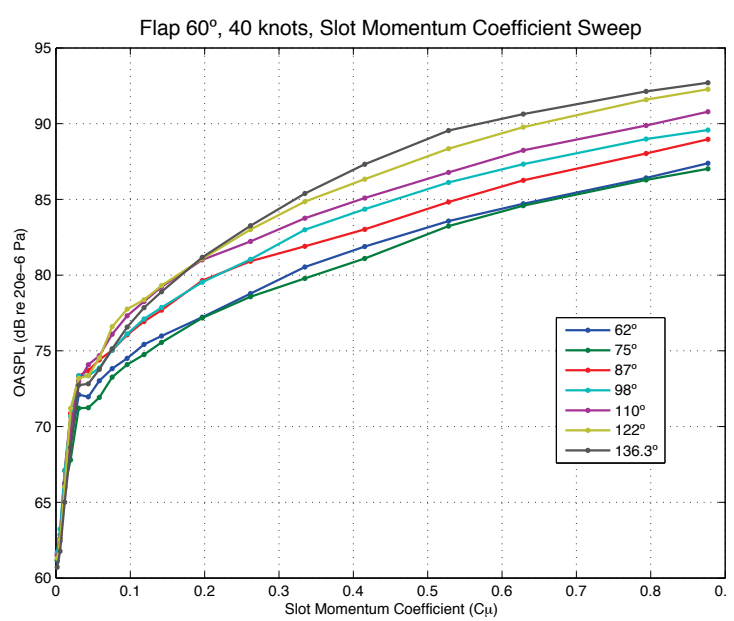

Figure 12. Variation of OASPL with slot mass flow rate for 7 microphones, $40 \mathrm{kts}$, flap $60^{\circ}$.

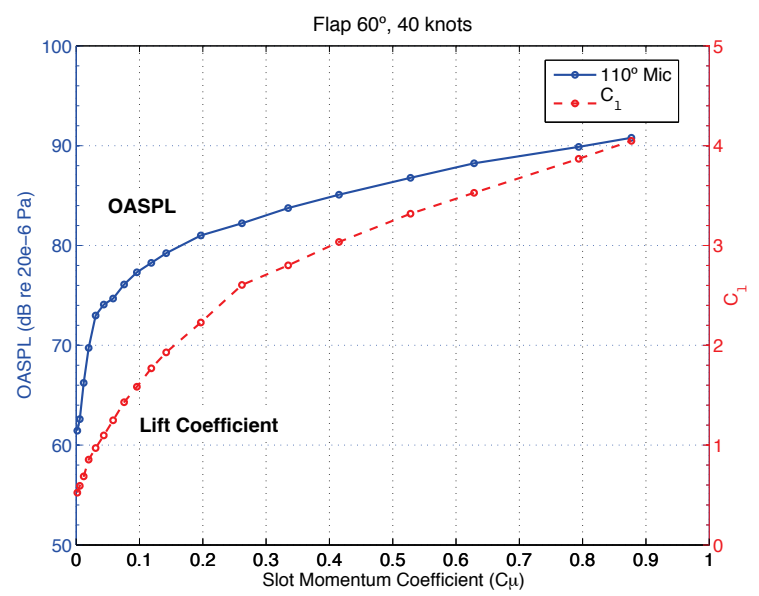

Figure 13. Variation of OASPL and model lift coefficient with slot momentum coefficient, $110^{\circ}$ microphone, $40 \mathrm{kts}$, flap $60^{\circ}$.

Figure 11 shows a set of 1/3-octave spectra for each of the 7 fixed microphones for the $40 \mathrm{kt}$, $60^{\circ}$ flap configuration. Both TE and LE slots are active from minimum to maximum slot flow rate, corresponding to $0.002 \leq$ $\mathrm{C} \mu \leq 0.88$. The plots show that the slot noise increases across all frequencies as the mass flow increases, with the highest rate of increase with $\mathrm{C} \mu$ at the lowest flow rates. At the lowest and highest $\mathrm{C} \mu$ values, the spectra are smooth, however several tones are present up to $10 \mathrm{kHz}$ at moderately low $\mathrm{C} \mu$. Similar trends are observed in Fig. 12, which plots OASPL for the 7 fixed microphones against $\mathrm{C} \mu$ for the same $40 \mathrm{kt}, 60^{\circ}$ flap configuration. A preliminary comparison of the variations in model lift coefficient and $110^{\circ}$ microphone OASPL level is shown in Fig 13. The trend of increasing $C_{L}$ with blowing rate is non-linear as is the case with OASPL, but the rate of increase at the lowest $\mathrm{C} \mu$ values is more moderate.

Similar plots of 1/3-octave spectra for the 7 microphones, and trends of $\mathrm{C}_{\mathrm{L}}$ and OASPL vs C $\mu$ for $100 \mathrm{kt}$, $60^{\circ}$ flap are shown in Fig. 14, 15, and 16. Note the range of $\mathrm{C} \mu$ from 0 to 0.14 is less than for the 40 kt case due to the higher tunnel velocity. The 1/3-octave plots also show a general trend of increasing spectral level with $\mathrm{C} \mu$, but with a small overall variation in level, and less prominent tonal activity. It is likely that the microphone self-noise at this higher velocity is a factor in the reduced effect of lower values of $\mathrm{C} \mu$ on spectral level, as seen in Fig. 14 and 15 , but also note the higher density of $\mathrm{C} \mu$ samples at the lower range for this condition. Fig. 16 shows that the $110^{\circ}$ 

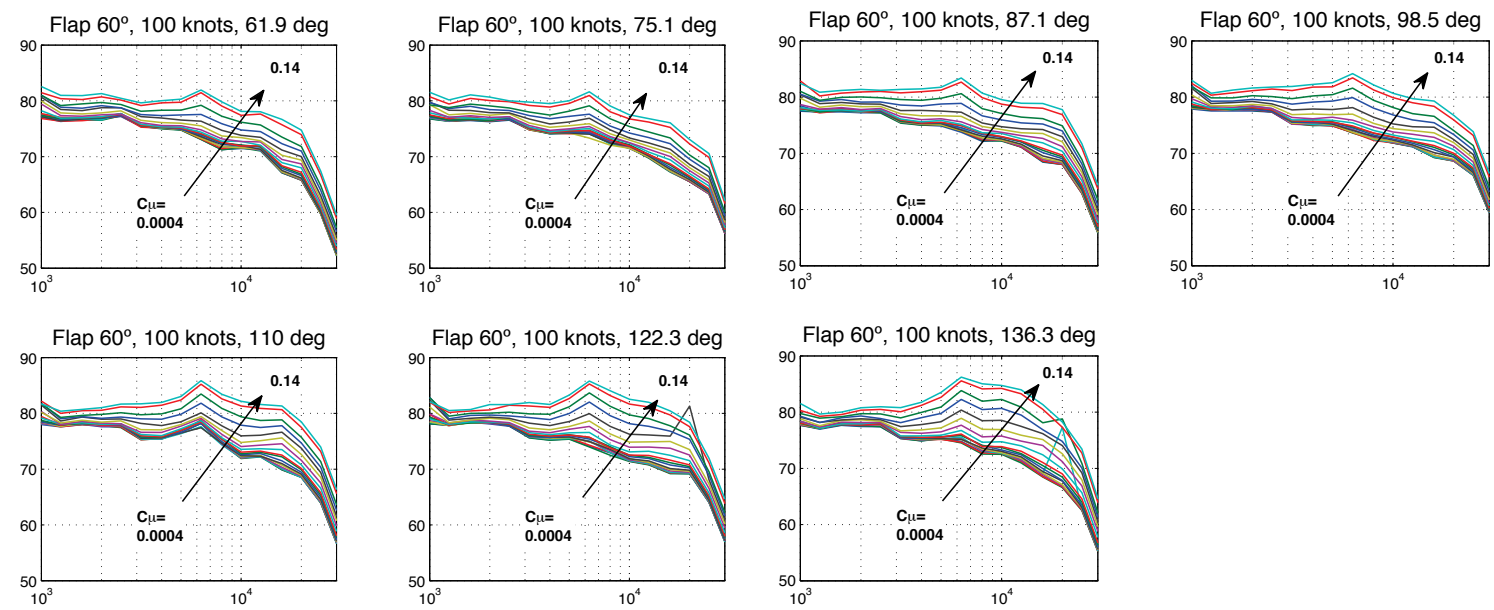

Figure 14. Effect of slot mass flow rate on 1/3-octave spectra for 7 microphones, $100 \mathrm{kts}$, flap $60^{\circ}$, $0.0004 \leq \mathrm{C} \mu \leq 0.14$.



Figure 15. Variation of OASPL with slot mass flow rate for 7 microphones, $100 \mathrm{kts}$, flap $60^{\circ}$.

microphone OASPL varies from about 88 to $91 \mathrm{~dB}$, while $\mathrm{C}_{\mathrm{L}}$ increases from about 0.5 to 2 as $\mathrm{C} \mu$ increases from 0 to 0.14 .

\section{TPS and slot blowing relative source strength}

An indication of the relative strengths of the noise sources may be gleaned from combined plots of slot blowing and TPS OASPL directivity, as is seen in Fig. 17 for the $40 \mathrm{kt}, 60^{\circ}$ flap condition. The lowest level curve is for TPS removed, slots off, and represents a combination of noise from the model airframe, sting, and pylon support with relatively small variation in directional level. The curves associated with slot blowing as $\mathrm{C} \mu$ varies from 0.06 to 0.88 range from roughly 12 to $26 \mathrm{~dB}$ higher. Operating the TPS units at full power adds $5-10 \mathrm{~dB}$ to the highest slot blowing level. This suggests that that the TPS dominates the OASPL field when it is running, and that slot-blowing noise overwhelms the airframe noise over most of the full range of $\mathrm{C} \mu$.



Figure 16. Variation of OASPL and model lift coefficient with slot mass flow rate at $110^{\circ}$ microphone, $100 \mathrm{kts}$, flap $60^{\circ}$

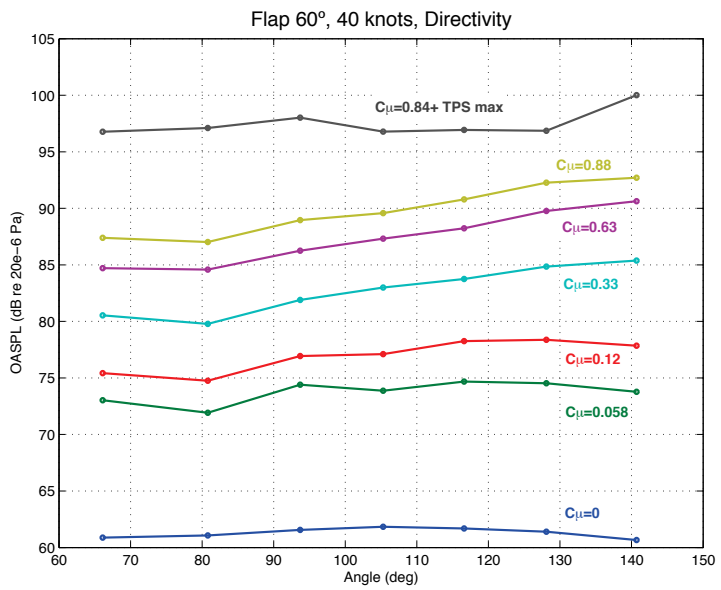

Figure 17. Comparison of directional OASPL levels for three configurations: a) clean wing $(\mathrm{C} \mu=$ 0, TPS removed), b) slow blowing (0.058 $\leq \mathrm{C} \mu \leq$ 0.88), c) max $C \mu$, TPS max (33,400 RPM), 40 kts, flap $\left.60^{\circ}\right)$. 




Figure 18. Comparison of directional OASPL levels for three configurations: a) clean wing $(\mathrm{C} \mu=$ 0 , TPS removed), b) slow blowing (0.012 $\leq \mathrm{C} \mu \leq$ 0.34), c) max $C \mu$, TPS max (33,400 RPM), $60 \mathrm{kts,}$ flap $60^{\circ}$ ).

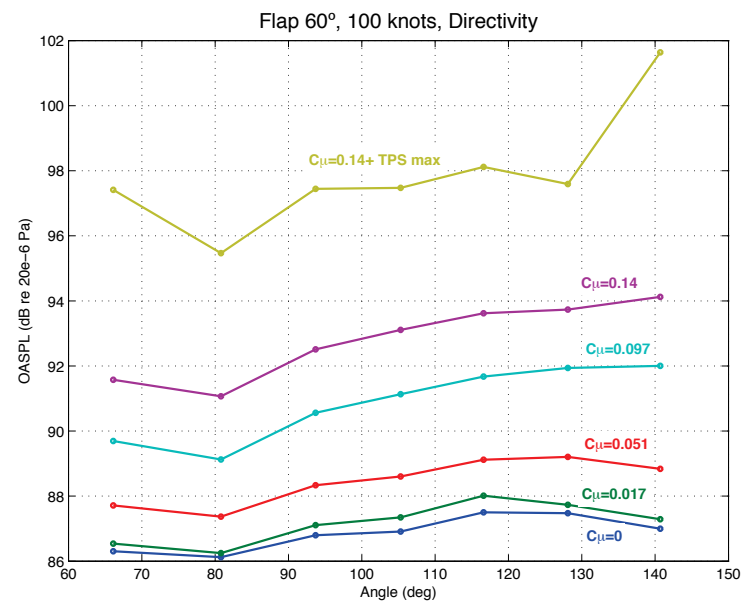

Figure 19. Comparison of directional OASPL levels for three configurations: a) clean wing $(\mathrm{C} \mu=$ 0, TPS removed), b) slow blowing $(0.017 \leq \mathrm{C} \mu \leq$ 0.14), c) $\max C \mu$, TPS max (33,400 RPM), $100 \mathrm{kts,}$ flap $60^{\circ}$ ).

Some similarities in the source build-up trends are observed with the conditions of $60 \mathrm{kt}, 60^{\circ}$ flap and $100 \mathrm{kt}, 60^{\circ}$ flap as shown in Fig. 18 and 19, respectively. At $60 \mathrm{kt}$, there is still a clear separation between the airframe/background noise at the lowest values of $\mathrm{C} \mu$, while microphone self-noise is comparable to the low-C $\mu$ directional OASPL level at $100 \mathrm{kts}$. Also, note that the directional variation in TPS noise is much greater at $100 \mathrm{kts}$ than at the two lower speeds.

\section{Phased Microphone Array Results}

Contamination of the slot noise source by the high-pressure air ducting and valves is a concern that can be addressed by examining array source location plots. Two coiled hoses external to the sting delivered the slot air. Figure 20 shows no evidence of sidelobes at frequencies ranging from $1 \mathrm{kHz}$ to $16 \mathrm{kHz}$ suggesting that contamination is minimal. A separate high-pressure air flow-path was used to drive the TPS units; air flowed through the sting, then through a model support blade at the end of the sting, and finally through an 6-inch flow through balance inside the model. Figure 21 shows that most of the acoustic energy from the TPS units was due only to the TPS. The lack of high-pressure air contamination to the TPS and slot-blowing model noise is consistent with the flow control metering systems located internally within the solid metal skin model.

Both the single microphones and the microphone array are subject to frequency-dependent directional variations that will be used to correct the data in future presentations. These corrections are moderate $(2-4 \mathrm{~dB})$ and different for the two systems. An estimate of the equivalent microphone spectra seen at the center of the array may be obtained by hemispherically integrating the array beamform maps and comparing with the spectra from a fixed microphone at a comparable location, as shown in Fig. 22. Although the data has not been corrected, the levels compare well below $10 \mathrm{kHz}$, but increase as much as $10 \mathrm{~dB}$ at higher frequencies. Corrections for directional sensor response should improve this comparison. 



Figure 20. Phased array images at $1 \mathrm{kHz}, 2 \mathrm{kHz}, 4 \mathrm{kHz}, 8 \mathrm{kHz}, 16 \mathrm{kHz}, 40 \mathrm{kts}$, flap $60^{\circ}$, clean wing, max slot blowing.
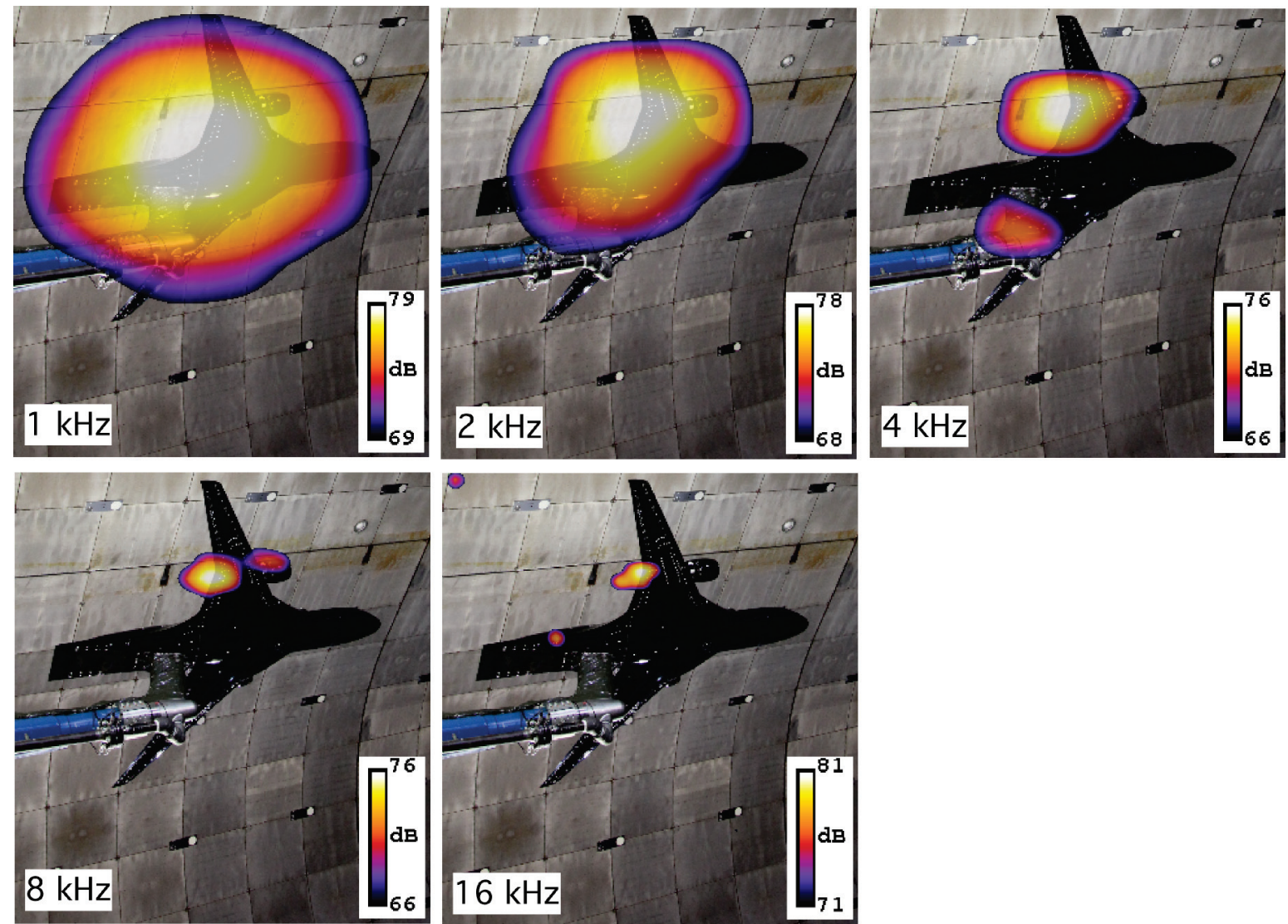

Figure 21. Phased array images at $1 \mathrm{kHz}, 2 \mathrm{kHz}, 4 \mathrm{kHz}, 8 \mathrm{kHz}$, and $16 \mathrm{kHz}, 40 \mathrm{kts}$, flap 60', high-pylon, max TPS, no slot blowing. 


\section{Concluding Comments}

Selected acoustic results for a recently completed test of the $11 \%$ AMELIA CESTOL test in the AEDC NFAC 40 - by 80 -Foot Wind Tunnel are presented to communicate the scope and trends of spectra and OASPL directivity. The full test matrix included variations in angle-of-attack from $-5^{\circ}$ to $25^{\circ}$, sideslip from $-10^{\circ}$ to $10^{\circ}$, forward velocity from 0 to $120 \mathrm{kts}$, flaps deflections of $0^{\circ}, 30^{\circ}, 60^{\circ}$, and $80^{\circ}, \mathrm{C} \mu$ from 0 to 0.9 , and TPS thrust from 0 to $77 \%$ of maximum. Only data from the $0^{\circ}$ angle-of-attack and $0^{\circ}$ sideslip at 40 kts, $60 \mathrm{kts}$, and $100 \mathrm{kts}$ are considered in the present discussion. Preliminary analyses indicate signal-tonoise of the 40-inch, 48-element phased array was excellent over the full range of test conditions. The seven single microphones showed a good signal-tonoise ratio for the $40 \mathrm{kt}$ case but a higher speeds the wind tunnel background noise exceeded the noise produced by the lowest slot blowing rates. Further processing, analysis, and reporting of the remaining data are in progress.

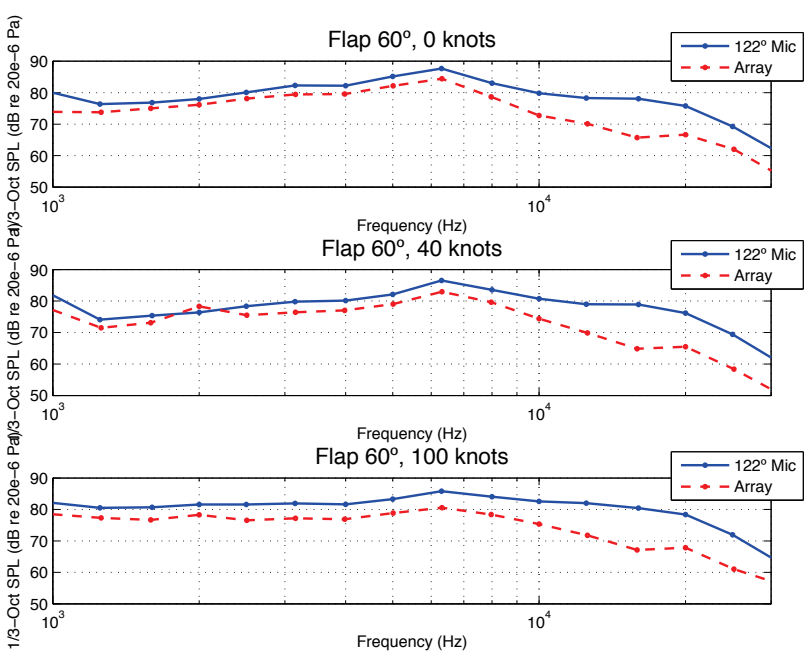

Figure 22. Comparison of $122^{\circ}$ single microphone to phased array integrated level at $0 \mathrm{kts}, 40 \mathrm{kts}$, and 100 kts, clean wing, max blowing. No corrections to directional response applied

\section{Appendix}

Table 1. Circulation control slot heights for each of the 8 wing slot sections, measurements are in mils (1 mil $=0.001$ inches).

\begin{tabular}{|c|c|c|c|c|c|c|}
\hline & \multicolumn{3}{|c|}{ Left Wing } & \multicolumn{3}{c|}{ Right Wing } \\
\cline { 2 - 7 } & average & $\min$ & $\max$ & average & $\min$ & $\max$ \\
\hline Leading Edge Inboard & 24.46 & 15.78 & 30.8 & 26.43 & 19.98 & 32.25 \\
\hline Leading Edge Outboard & 24.39 & 15 & 36.25 & 23.44 & 13.5 & 35.45 \\
\hline Trailing Edge Inboard & 47.05 & 37.01 & 53.75 & 27.81 & 37.05 & 56.55 \\
\hline Trailing Edge Outboard & 24.53 & 15.56 & 46.55 & 23.68 & 15.35 & 37.9 \\
\hline
\end{tabular}


Table 2. Sensor locations in wind tunnel coordinate system as shown in Fig. 3. The origin is located at the center of the turntable, measurements are inches. Emission angle is calculated from the model acoustic center.

\begin{tabular}{|c|c|c|c|c|c|}
\hline Sensor & $\mathrm{Xw}$ & $\mathrm{Yw}$ & $\mathrm{Zy}$ & $\mathrm{Q}$ & $\mathrm{R}$ \\
\hline Mic 1 & -164.9 & -247.3 & 76.4 & 61.9 & 336.1 \\
\hline Mic 2 & -93.5 & -234.8 & 74.9 & 75.1 & 304.9 \\
\hline Mic 3 & -40.9 & -225.5 & 74.9 & 87.1 & 290.9 \\
\hline Mic 4 & 4.2 & -217.5 & 74.9 & 98.5 & 286.3 \\
\hline Mic 5 & 49.6 & -209.5 & 74.9 & 110.0 & 289.0 \\
\hline Mic 6 & 101.9 & -200.3 & 74.9 & 122.3 & 301.0 \\
\hline Mic 7 & 174.2 & -187.6 & 74.9 & 136.3 & 331.2 \\
\hline Phased Array & 90.6 & 218.2 & 67.6 & 119.6 & 303.2 \\
\hline $\begin{array}{c}\text { Acoustic Center } \\
\left(0^{\circ} \alpha, 0^{\circ} \beta\right)\end{array}$ & -29.272 & 7.154 & 249.043 & & \\
\hline
\end{tabular}

\section{Acknowledgements}

The AMELIA test was funded by NASA's Subsonic Fixed Wing Program as a NASA Research Agreement (NRA) with Cal Poly University (NASA NNL07AA55C). The acoustic portion of this test was supported directly by the Subsonic Fixed Wing Program.

\section{References}

1 "Subsonic Fixed Wing - Research Overview", http://www.aeronautics.nasa.gov/fap/sfw_research_overview_feature.html

2 Jameson, K., Marshal, D., Golden, R., Paciano, E., Englar, R., Gaeta, R., Paterson, J, Mason, D., "Part1: The Wind Tunnel Model Design and Fabrication of Cal Poly's AMELIA 10 Foot Span Hybrid Wing-Body Low Noise CESTOL Aircraft," $49^{\text {th }}$ AIAA Aerospace Sciences Meeting, Orlando FL, AIAA-2011-1306, January 4-7, 2011.

${ }^{3}$ Jameson, K., Marshal, Ehman, R., Paciano, E., Englar, Horne, W.C., "Part 2: Preparation for Wind Tunnel Model Testing and Verification of Cal Poly's AMELIA 10 Foot Span Hybrid Wing-Body Low Noise CESTOL Aircraft,", $49^{\text {th }}$ AIAA Aerospace Sciences Meeting, Orlando, FL, AIAA-2011-1307, January 4-7, 2011.

${ }^{4}$ Englar, R., Gaetam R., Lee, W., Leone, V., "Development of Pneumatic Over-the-Wing Powered-Lift Technology: Part 1: Aerodynamic/Propulsive," $27^{\text {th }}$ AIAA Applied Aerodynamic Conference, San Antonio, TX, AIAA-2009-3942, June 22-25, 2009.

5 Salikudding, M., Brown, W. H., Ahuja, K. K., "Noise from a Circulation Control Wing with Upper Surface Blowing," Journal of Aircraft, Vol 24, No.1, January 1987, pp 55-64.

${ }^{6}$ Patterson, G. T., Joshi, M. C., Maus, J. R. , "Experimental Investigation of the Aeroacoustic Characteristics of Model Slot Nozzels with Straight Flaps," 2 ${ }^{\text {nd }}$ AIAA Aero-Acoustics Conference, Hampton, VA, AIAA-75-471, March 24-26, 1975.

${ }^{7}$ Pott-Pollenske, M. and Pfingsten, K. C., "Aeroacoustic Performance of and Airfoil with Circulation Control," $16^{\text {th }}$ AIAA/CEAS Aeroacoustics Conference, Stockholm, Sweden, AIAA-2010-3881, June 7-9, 2010.

${ }^{8}$ Schmitz, F. H., Allmen, J. R., Soderman, P. T., "Modification of the Ames 40- by 80-Foot Wind Tunnel for Component Acoustic Testing for the Second Generation of Supersonic Transport," NASA Technical Memorandum 108850, October 1994.

${ }^{9}$ Soderman, P. T., Schmitz, F. H., Allen, C. S., Jaeger, S. M., Sacco, J. N., Mosher, M., Hayes, J. A., "Design of a Deep Acoustic Lining for the 40- by 80-Foot Wind Tunnel Test Section," NASA/TP-2002-211850, 2002.

${ }^{10}$ Soderman, P. T., Jaeger, S. M., Hayes, J. A., Allen, C.S., “Acoustic Performance of the 40-x by 80-Foot Wind Tunnel Section Deep Acoustic Lining," NASA/TP-2002-211851, November, 2002.

${ }^{11}$ Allen, C.S., Jaeger, S.M., Soderman, P.T., "Background Noise Sources and Levels in the NASA Ames 40- by 80-Foot Wind Tunnel at the Turn of the Century: A Status Report," NASA/TP-2003-212259, November 2003.

${ }^{12}$ Horne, W. C., Burnside, N.J., Soderman P. T., Jaeger, S. M., Reinero, B. R., James, K. D., Arledge, T. K., “Aeroacoustic Study of a $26 \%$ Semi-span Model of a Boeing 777 Wing in the NASA Ames 40- by 80-Foot Wind Tunnel," NASA/TP-2004212802, October, 2004. 